\title{
Associations of Polymorphisms in the Apolipoprotein APOA1-C3-A5 Gene Cluster with Acute Coronary Syndrome
}

\author{
Yan Ding, ${ }^{1}$ Ming An Zhu,, ${ }^{2}$ Zhi Xiao Wang, ${ }^{3}$ Jing Zhu, ${ }^{2}$ Jing Bo Feng, ${ }^{1}$ and Dong Sheng Li1 \\ ${ }^{1}$ Hubei Provincial Key Laboratory of Embryonic Stem Cell Research, Tai He Hospital, Hubei University of Medicine, \\ 32 S. Renmin Road, Shiyan, Hubei 442000, China \\ ${ }^{2}$ Clinical Laboratory, Tai He Hospital, Hubei University of Medicine, 32 S. Renmin Road, Shiyan, Hubei 442000, China \\ ${ }^{3}$ Cardiovascular Department, Taihe Hospital, Hubei University of Medicine, 32 S. Renmin Road, Shiyan, Hubei 442000, China
}

Correspondence should be addressed to Yan Ding, dyywzx@163.com

Received 10 February 2012; Revised 8 March 2012; Accepted 22 March 2012

Academic Editor: Momiao Xiong

Copyright () 2012 Yan Ding et al. This is an open access article distributed under the Creative Commons Attribution License, which permits unrestricted use, distribution, and reproduction in any medium, provided the original work is properly cited.

\begin{abstract}
Background. Acute coronary syndromes (ACSs) are clinically cardiovascular events associated with dyslipidemia in common. Single nucleotide polymorphisms (SNPs) and haplotypes in the APOA1/C3/A5 gene cluster are associated with diabetes and familial combined hyperlipidaemia $(\mathrm{FCH})$. Little is known about whether the polymorphisms in these genes affect lipid homeostasis in patients with ACSs. The present paper aimed to examine these associations with 4 SNPs in the APOA1 $-75 \mathrm{G}>$ A, the APOC3 $-455 \mathrm{~T}>\mathrm{C}$, and APOA5 - 1131T > C, c.553G > T variant to ACSs in Chinese Han. Methods. Chinese Han of 229 patients with ACSs and 254 unrelated controls were analyzed. Four SNPs in APOA1/C3/A5 cluster were genotyped and lipid was determined. Results. Our data show that minor allelic frequencies of APOC3 - 455T > C, APOA5 - 1131T > C, and c.553G $>$ T polymorphisms in patients with ACSs were significantly higher than control group $(P<0.05)$. Furthermore, the 3 polymorphic sites were strongly of linkage disequilibrium, and minor alleles of 3 SNP sites had higher TG level than wild alleles $(P<0.05)$, APOC3 $-455 \mathrm{C}$ and APOA5 c.553T allele carriers also had lower level of HDL-C. Conclusions. The minor alleles of APOC3 - 455T > C, APOA5 $-1131 \mathrm{~T}>\mathrm{C}$, and c.553G > T polymorphisms are closely associated with ACSs.
\end{abstract}

\section{Introduction}

Acute coronary syndromes (ACSs), including unstable angina (UA) and acute myocardial infarction (AMI), are clinically cardiovascular events resulted from the rupture of atherosclerotic plaque, followed by inflammation associated with acute-phase response. Atherosclerosis, the major event leading to ACSs, is characterized by the events following accumulation of lipids and fibrous elements in coronary arteries, several risk factors such as genetic and environmental have been identified; most importantly levels of HDL, triglycerides, lipoprotein (a), diabetes mellitus, smoking, and hypertension $[1,2]$. Meanwhile, dyslipidemia is common and associated with increased mortality rates in hospitalized patients with ACS [3]. Dyslipidemia often occurs in ACSs patients, however, the incidence of underlying mechanisms in this disease remain poorly understood. The Apolipoprotein A1-C3-A4-A5 gene cluster on chromosome 11q23 (Apo11q) is among the most well-characterized regions of the human genome with reference to their dynamic association with plasma lipids and lipoproteins [4]. The associated haplotypes constitute a highly informative genetic marker [5].

Extensive interactions both within and between the genetic variants within this cluster contribute to the quantitative variation in the blood lipid phenotypes [6]. The SNPs in the Apo11q region, particularly the $-455 \mathrm{~T}>\mathrm{C}$ of the APOC3 gene [7], as well as $-1131 \mathrm{C}>\mathrm{T}$ promoter SNP and 
S19W SNP in exon 2 of the APOA5 gene [8, 9], have been shown to independently and in tandem, regulate plasma TG levels [10]. The two promoter SNPs, $-75 \mathrm{G}>\mathrm{A}$ and $+83 \mathrm{C}>$ $\mathrm{T}$ in the APOAl gene, have shown strong association with HDL-C and ApoA1 levels [11].

The aim of this study was to analyze the relationship of SNPs in the APOA1/C3/A4/A5 cluster with ACSs in Chinese Han.

\section{Materials and Methods}

2.1. Study Population. The patient group consisted of 229 unrelated patients ranging in age from 40 to 75 years old (mean, 59 years old); all had symptoms of ischemia that were verified by electrocardiography [ST segment depression $(\geq 0.1 \mathrm{~mm})$, T-wave inversion $(\geq 0.1 \mathrm{~mm})]$, or increased levels of biochemical markers (creatine kinase myoglobin binding isoenzyme [CK-MB], $>6.6 \mu \mathrm{g} / \mathrm{L}$ or troponin I [TnI], $>0.3 \mu \mathrm{g} / \mathrm{L}[0.3 \mathrm{ng} / \mathrm{mL}])$. The diagnosis of ACS was established on the basis of current definitions [12].

Control group consisted of 254 unrelated healthy people all in mean age at 59 years old. The inclusion criteria for the control group were without a clinical history of CVD, cardiovascular risk factorshistory, or diagnosis of atherosclerosis, vascular disease, chronic heart failure, and arrhythmias, diabetes mellitus, or cancer, and those with a normal electrocardiograph and normal blood chemistry values were included.

After an overnight fast for a minimum of $12 \mathrm{~h}$, blood was drawn into EDTA-containing tubes for analysis of lipid profiles. Plasma was prepared by immediate centrifugation $\left(1,800 \mathrm{~g}, 15 \mathrm{~min}, 4^{\circ} \mathrm{C}\right)$, and samples were stored at $-80^{\circ} \mathrm{C}$ until further analyses. Serum total cholesterol, low-density lipoprotein (LDL) cholesterol, HDL cholesterol, and triglyceride (TG) concentrations were measured enzymatically on a Hitachi 7450 Analyzer (Hitachi, Japan) using Roche reagents.

2.2. Genetic Analysis. DNA was isolated from peripheral blood leukocytes by a standard salting out method. Details of PCR primers, annealing conditions, and restriction enzyme digestion were according to others [13-15]. In short, the genomic regions encompassing the polymorphic sites were PCR amplified using site-specific primers, restriction digested with appropriate restriction enzymes (Msp I restriction enzyme for APOA1 $-75 \mathrm{G}>\mathrm{A}$ and APOA 5 c.553G $>$ T, BseG I for APOC3 $-455 \mathrm{~T}>\mathrm{C}$, Mse I for APOA5 - 1131T > $\mathrm{C}$ ), and the digests were resolved on $2 \%$ agarose gel for the APOA1 and the APOA5 SNPs, while the APOC3 genotypes were resolved by $6 \%$ polyacrylamide gel electrophoresis (PAGE).

2.3. Statistical Analysis. The statistical analyses were carried out with SPSS 14.0 software. All data are expressed as mean \pm standard deviation (SD). Frequencies of the alleles were estimated by gene counting. Agreement of genotype frequencies with Hardy-Weinberg equilibrium expectations was tested using $\chi^{2}$ test. The clinical characteristics of study subjects were compared by unpaired Student's $t$-test. The
TABLE 1: General clinical information and blood fat concentration comparison of the two groups.

\begin{tabular}{lccc}
\hline & $\begin{array}{c}\text { ACS group } \\
(n=229)\end{array}$ & $\begin{array}{c}\text { Control } \\
\text { group } \\
(n=254)\end{array}$ & $P$ \\
\hline Gender $($ male/female $)$ & $128 / 101$ & $137 / 117$ & NS \\
Age $($ mean year $)$ & $59.1 \pm 9.4$ & $59.3 \pm 9.6$ & NS \\
BMI $\left(\mathrm{kg} / \mathrm{m}^{2}\right)$ & $23.24 \pm 3.26$ & $22.75 \pm 2.97$ & $<0.01$ \\
SBP $(\mathrm{mmHg})$ & $126.10 \pm 12.43$ & $121.93 \pm 3.10$ & $<0.01$ \\
DBP $(\mathrm{mmHg})$ & $74.4 \pm 4.6$ & $74.8 \pm 4.8$ & NS \\
Total cholesterol & $5.04 \pm 1.33$ & $4.77 \pm 1.07$ & $<0.01$ \\
(TC, mmol/L) & $2.02 \pm 0.52$ & $1.38 \pm 0.39$ & $<0.01$ \\
Triglyceride & $1.03 \pm 0.34$ & $1.28 \pm 0.31$ & $<0.01$ \\
(TG, mmol/L) & $3.87 \pm 0.91$ & $2.44 \pm 0.68$ & $<0.01$ \\
HDL-C $(\mathrm{mmol} / \mathrm{L})$ & $5.04 \pm 1.33$ & $4.77 \pm 1.07$ & $<0.01$ \\
\hline LDL-C $(\mathrm{mmol} / \mathrm{L})$ & & & \\
Blood glucose $(\mathrm{mmol} / \mathrm{L})$ & & & \\
\hline
\end{tabular}

Systolic blood pressure and diastolic blood pressure. ACS: coronary artery disease; BMI: body mass index; HDL: high-density lipoprotein; LDL: lowdensity lipoprotein.

lipid levels difference among every genotype were tested with ANCOVA. The $\chi^{2}$ test was used to compare the qualitative data. Logistic regression analysis models were used to evaluate the haplotypes as possible risk factors. To determine the extent of LD in our sample, standardized LD coefficients $D^{\prime}$ was calculated for all pairs of polymorphisms.

\section{Results}

3.1. Characteristics of Controls and Patients. General characteristics of 229 ACS patients and 254 healthy controls are shown in Table 1. ACS patients showed higher systolic blood pressure, TG, total and LDL-cholesterol, and glucose but lower HDL-cholesterol levels than controls.

3.2. Allele Frequency and Linkage Disequilibrium. Genotype distributions for these polymorphisms were in HardyWeinberg equilibrium. As shown in Table 2, the minor allelic frequencies of $-1131 \mathrm{~T}>\mathrm{C}$ and c. $553 \mathrm{G}>\mathrm{T}$ polymorphisms of APOA5 in patients with ACS (41.3\% and 9.8\%) were significantly higher than those of the control subjects (31.1\% and $4.9 \%$, resp.). Frequency of C allele of APOC $3-455 \mathrm{~T}>$ $\mathrm{C}$ in patients with ACS was also significantly higher than that of normal subjects (26.9\% and $17.3 \%$, resp.). However, this difference was not observed in that of APOA1 $-75 \mathrm{G}>\mathrm{A}$ $(P>0.05)$ (Table 2).

To determine the extent of LD in our study sample, standardized LD coefficients $D^{\prime}$ was calculated for all pairs of polymorphisms. Table 3 shows the LD matrix generated using $D^{\prime}$. As shown in Table 3, except for APOA $1-75 \mathrm{G}>\mathrm{A}$, the other 3 polymorphic sites were in strong linkage disequilibrium $\left(D^{\prime}>0.8\right)$.

3.3. Lipid Level and Association Analysis. We found that APOC3 -455T > C, APOA5 c.553G > T, and $-1131 \mathrm{~T}>\mathrm{C}$ 
TABLE 2: Comparison of genotype frequencies and Hardy-Weinberg equilibrium test results of the four polymorphisms in the apolipoprotein A1/C3/A5 gene cluster between control and ACS group.

\begin{tabular}{|c|c|c|c|c|}
\hline & & $\begin{array}{c}\text { ACS } \\
(n=229)\end{array}$ & $\begin{array}{l}\text { Controls } \\
(n=254)\end{array}$ & $P$ \\
\hline \multirow{5}{*}{ APOA $1-75 G>A$} & GG & $41 \%(94)$ & $42.5 \%(108)$ & \\
\hline & GA & $41.5 \%(95)$ & $48.8 \%(124)$ & 0.012 \\
\hline & AA & $17.5 \%(40)$ & $8.7 \%(22)$ & \\
\hline & $\mathrm{G}$ & $61.8 \%(283)$ & $66.9 \%(340)$ & \\
\hline & $\mathrm{A}$ & $39.2 \%(175)$ & $33.1 \%(168)$ & 0.096 \\
\hline \multirow{5}{*}{ APOC $3-455 \mathrm{~T}>\mathrm{C}$} & TT & $20 \%(46)$ & $26.4 \%(67)$ & \\
\hline & $\mathrm{TC}$ & $50 \%(115)$ & $53.9 \%(137)$ & 0.026 \\
\hline & $\mathrm{CC}$ & $30 \%(68)$ & $19.7 \%(50)$ & \\
\hline & $\mathrm{T}$ & $73.1 \%(207)$ & $82.7 \%(271)$ & \\
\hline & $\mathrm{C}$ & $26.9 \%(251)$ & $17.3 \%(237)$ & 0.012 \\
\hline \multirow{5}{*}{ APOA $5-1131 \mathrm{~T}>\mathrm{C}$} & TT & $38.9 \%(89)$ & $52 \%(132)$ & \\
\hline & $\mathrm{TC}$ & $39.7 \%(91)$ & $33.9 \%(86)$ & 0.01 \\
\hline & $\mathrm{CC}$ & $21.4 \%(49)$ & $14.1 \%(36)$ & \\
\hline & $\mathrm{T}$ & $58.7 \%(269)$ & $68.9 \%(350)$ & \\
\hline & $\mathrm{C}$ & $41.3 \%(189)$ & $31.1 \%(158)$ & 0.001 \\
\hline \multirow{5}{*}{ APOA5 c.553G > T } & GG & $81.2 \%(186)$ & $90.9 \%(231)$ & \\
\hline & GT & $17.9 \%(41)$ & $8.3 \%(21)$ & 0.007 \\
\hline & $\mathrm{TT}$ & $0.9 \%(2)$ & $0.8 \%(2)$ & \\
\hline & $\mathrm{G}$ & $90.2 \%(413)$ & $95.1 \%(483)$ & \\
\hline & $\mathrm{T}$ & $9.8 \%(45)$ & $4.9 \%(25)$ & 0.003 \\
\hline
\end{tabular}

TABLE 3: Standardized linkage disequilibrium coefficient $\left(D^{\prime}\right)$ among four APOA1/C3/A5.

\begin{tabular}{lccc}
\hline & $\begin{array}{c}\text { APOC3 } \\
-455 \mathrm{~T}>\mathrm{C}\end{array}$ & $\begin{array}{c}\text { APOA5 } \\
-1131 \mathrm{~T}>\mathrm{C}\end{array}$ & $\begin{array}{c}\text { APOA5 } \\
\text { c.553G }>\mathrm{T}\end{array}$ \\
\hline APOA1 $-75 \mathrm{G}>\mathrm{A}$ & 0.19 & 0.20 & 0.05 \\
APOC3 $-455 \mathrm{~T}>\mathrm{C}$ & & 0.83 & 0.86 \\
APOA5 $-1131 \mathrm{~T}>\mathrm{C}$ & & & 0.92 \\
\hline
\end{tabular}

SNPs were all significantly associated with lipid levels. Specifically, the minor allele's carrier of the three SNPs showed a significant higher triglyceride, and APOC3 -455C and APOA5 c.553T allele carriers also showed a significant lower HDL cholesterol level than subjects with wild genotypes (Table 4). No significant differences of triglycerides and HDL cholesterol levels genotypes were found in APOA1 -75G > A.

Multiple logistic regression for best selection model in above genotypes after adjusting age, gender, and body mass index is shown in Table 5; we can see that except for APOA1 $-75 \mathrm{G}>\mathrm{A}$, the minor allele of each of other three polymorphisms (APOC3 - 455T > C, and the APOA5, -1131T >C and c.553G $>$ T) were associated with ACS.

\section{Conclusion}

In this study, the frequency of the APOA5 c.553T allele in ACS patient group was significantly higher than that of the controls. Compared with the participants with major alleles (APOA5 - 1131TT and c.553GG), those homozygous for both SNPs (APOA5 -1131CC and c.553TT) had higher triglyceride concentrations (Table 4). Subjects homozygous for c.553TT also had higher HDL-C than those with c.553GG. All these data suggested the importance of APOA5 in the regulation of plasma triglyceride concentrations. Furthermore, pair wise linkage disequilibrium comparison performed in this study betweenAPOC3 and APOA5 demonstrated that they are linked $\left(D^{\prime}<0.8\right)$, suggesting cooperation mechanisms for the associations with plasma lipoproteins and related traits.

\section{Discussion}

ACSs are a multifactor disease in which a multitude of lifestyle and genetic factors contribute to the development and outcome of the disease [16]. Many papers show that apolipoprotein A1/C3/A4/A5 gene cluster is associated with premature coronary artery disease [17] and serum lipid levels [18-25]. Recent findings indicate that APOA5 could also influence cholesterol homeostasis and probably play a role in hypertriglyceridemia associated with diabetes and inflammation [20].

The frequency of APOC3 $-455 \mathrm{C}$ allele in ACSs patients was significantly higher than that of normal subjects. This genetic variation was associated with variation in plasma concentrations of TG and HDL cholesterol in a manner consistent with many other reports from diverse populations $[26,27]$. Specifically, we found that the $\mathrm{C}$ allele was associated 
TABLE 4: Comparison of HDL-C and TG level of the four polymorphisms in the apolipoprotein A1/C3/A5 gene cluster of the study participants.

\begin{tabular}{|c|c|c|c|c|c|}
\hline & & & & & \\
\hline & & Mean \pm SD & $P$ & Mean \pm SD & $P$ \\
\hline APQA $1-75 G>A$ & GG & $1.72 \pm 0.37$ & NIS & $1.19 \pm 0.34$ & NTC \\
\hline & $\mathrm{GA}+\mathrm{AA}$ & $1.58 \pm 0.34$ & NS & $1.17 \pm 0.24$ & NS \\
\hline APOC $3-455 \mathrm{~T}>\mathrm{C}$ & $\mathrm{TT}$ & $1.43 \pm 0.34$ & $<001$ & $1.22 \pm 0.36$ & 0001 \\
\hline 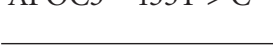 & $\mathrm{TC}+\mathrm{CC}$ & $2.06 \pm 0.45$ & $<0.01$ & $1.04 \pm 0.30$ & $<0.01$ \\
\hline$A P O A 5-1131 T>C$ & $\mathrm{TT}$ & $1.32 \pm 0.38$ & & $1.15 \pm 0.43$ & \\
\hline גו & $\mathrm{TC}+\mathrm{CC}$ & $2.09 \pm 0.44$ & $<0.01$ & $1.10 \pm 0.38$ & NS \\
\hline APOA $5,553 G>T$ & GG & $1.47 \pm 0.32$ & 001 & $1.24 \pm 0.41$ & 001 \\
\hline Ar & $\mathrm{GT}+\mathrm{TT}$ & $2.02 \pm 0.48$ & $<0.01$ & $0.97 \pm 0.31$ & $<0.01$ \\
\hline
\end{tabular}

TABLE 5: Odds ratios of ACS and 95\% confidence intervals (CI) in relation to the presence of different alleles of apolipoprotein gene after adjusting for age, gender, and BMI values.

\begin{tabular}{lccc}
\hline & Variable & Odds ratio $(95 \%$ CI $)$ & $P$ \\
\hline APOA $1-75 G>$ A & (AA and GA)/GG & $0.913(0.6358-1.313)$ & NS \\
APOC3 $-455 \mathrm{~T}>$ C & (GG and GC)/CC & $2.043(1.413-3.956)$ & 0.000 \\
APOA $5-1131 \mathrm{~T}>\mathrm{C}$ & (CC and CT)/TT & $3.702(2.185-5.445)$ & 0.001 \\
APOA5 c.553G $>$ T & (TT and TG) $/ \mathrm{GG}$ & $2.344(1.477-4.290)$ & 0.001 \\
\hline
\end{tabular}

with higher TG and lower HDL cholesterol; in addition, population studies have elucidated genetic association of APOC3 with HDL cholesterol levels [28]. These observations suggest that the functional APOC3 SNP mediates the widely replicated associations of hypertriglyceridemia and lower HDL cholesterol.

In summary, we demonstrated that common variants of APOA1, APOC3, and APOA5 genes are associated with ACS and contribute to the variation in human plasma TG levels. Therefore, APOA5 variant was a significant predictor for high triglyceride/HDL risk and the APOA1/C3/A4/A5 haplotypes affected dyslipidemia appreciably among ethnic Chinese. Variations of these genes may be associated with the development of ACSs. They could be served as a useful genetic marker for diagnosis of ACSs.

\section{Acknowledgment}

This paper was supported by graduate Research Qi Dong Jin of Hubei University of Medicine 2008 QDJ21.

\section{References}

[1] I. M. Stylianou, R. C. Bauer, M. P. Reilly, and D. J. Rader, "Genetic basis of atherosclerosis: insights from mice and humans," Circulation Research, vol. 110, no. 2, pp. 337-355, 2012.

[2] W. R. Maclellan, Y. Wang, and A. J. Lusis, "Systems-based approaches to cardiovascular disease," Nature Reviews Cardiology, vol. 9, no. 3, pp. 172-184, 2012.

[3] M. Miller, C. P. Cannon, S. A. Murphy, J. Qin, K. K. Ray, and E. Braunwald, "Impact of triglyceride levels beyond low-density lipoprotein cholesterol after acute coronary syndrome in the
PROVE IT-TIMI 22 trial," Journal of the American College of Cardiology, vol. 51, no. 7, pp. 724-730, 2008.

[4] L. A. Pennacchio, M. Olivier, J. A. Hubacek et al., "An apolipoprotein influencing triglycerides in humans and mice revealed by comparative sequencing," Science, vol. 294, no. 5540, pp. 169-173, 2001.

[5] S. C. Hamon, S. L. R. Kardia, E. Boerwinkle et al., "Evidence for consistent intragenic and intergenic interactions between SNP effects in the APOA1/C3/A4/A5 gene cluster," Human Heredity, vol. 61, no. 2, pp. 87-96, 2006.

[6] Q. F. Wang, X. Liu, J. O'Connell et al., "Haplotypes in the APOA1-C3-A4-A5 gene cluster affect plasma lipids in both humans and baboons," Human Molecular Genetics, vol. 13, no. 10, pp. 1049-1056, 2004.

[7] G. T. Russo, J. B. Meigs, L. A. Cupples et al., "Association of the Sst-I polymorphism at the APOC3 gene locus with variations in lipid levels, lipoprotein subclass profiles and coronary heart disease risk: the Framingham offspring study," Atherosclerosis, vol. 158, no. 1, pp. 173-181, 2001.

[8] P. J. Talmud, E. Hawe, S. Martin et al., "Relative contribution of variation within the APOC3/A4/A5 gene cluster in determining plasma triglycerides," Human Molecular Genetics, vol. 11, no. 24, pp. 3039-3046, 2002.

[9] E. Olano-Martin, E. C. Abraham, R. Gill-Garrison et al., "Influence of apoA-V gene variants on postprandial triglyceride metabolism: impact of gender," Journal of Lipid Research, vol. 49, no. 5, pp. 945-953, 2008.

[10] D. M. Hallman, S. R. Srinivasan, W. Chen, E. Boerwinkle, and G. S. Berenson, "Longitudinal analysis of haplotypes and polymorphisms of the APOA5 and APOC3 genes associated with variation in serum triglyceride levels: the Bogalusa Heart Study," Metabolism, vol. 55, no. 12, pp. 1574-1581, 2006.

[11] M. I. Kamboh, C. E. Aston, C. M. Nestlerode, A. E. McAllister, and R. F. Hamman, "Haplotype analysis of two APOA1/MspI polymorphisms in relation to plasma levels of Apo A-I and 
HDL-cholesterol," Atherosclerosis, vol. 127, no. 2, pp. 255-262, 1996.

[12] A. Mälarstig, T. Tenno, N. Johnston et al., "Genetic variations in the tissue factor gene are associated with clinical outcome in acute coronary syndrome and expression levels in human monocytes," Arteriosclerosis, Thrombosis, and Vascular Biology, vol. 25, no. 12, pp. 2667-2672, 2005.

[13] A. Matsunaga, H. Arishima, H. Niimura et al., "Strong linkage disequilibrium and association of $-1131 \mathrm{~T}>\mathrm{C}$ and c.553G $>\mathrm{T}$ polymorphisms of the apolipoprotein A5 gene with hypertriglyceridemia in a Japanese populatio," Circulation Journal, vol. 71, no. 5, pp. 746-752, 2007.

[14] C. K. Heng, P. S. Low, and N. Saha, "Variations in the promoter region of the apolipoprotein A-1 gene influence plasma lipoprotein(a) levels in Asian Indian neonates from Singapore," Pediatric Research, vol. 49, no. 4, pp. 514-518, 2001.

[15] S. Taş, "Strong association of a single nucleotide substitution in the 3'-untranslated region of the apolipoprotein-CIII gene with common hypertriglyceridemia in Arabs," Clinical Chemistry, vol. 35, no. 2, pp. 256-259, 1989.

[16] C. K. Glass and J. L. Witztum, "Atherosclerosis: the road ahead," Cell, vol. 104, no. 4, pp. 503-516, 2001.

[17] L. Qi, S. Liu, N. Rifai, D. Hunter, and F. B. Hu, "Associations of the apolipoprotein $A 1 / C 3 / A 4 / A 5$ gene cluster with triglyceride and HDL cholesterol levels in women with type 2 diabetes," Atherosclerosis, vol. 192, no. 1, pp. 204-210, 2007.

[18] J. Shanker, G. Perumal, V. S. Rao et al., "Genetic studies on the APOA1-C3-A5 gene cluster in Asian Indians with premature coronary artery disease," Lipids in Health and Disease, vol. 7, article 33, 2008.

[19] R. X. Yin and C. Q. Lai, "Apolipoprotein A1/C3/A5 haplotypes and serum lipid levels," Lipids in Health and Disease, vol. 10, article 140, 2011.

[20] K. L. Chien, M. F. Chen, H. C. Hsu et al., "Genetic association study of $A P O A 1 / C 3 / A 4 / A 5$ gene cluster and haplotypes on triglyceride and HDL cholesterol in a community-based population," Clinica Chimica Acta, vol. 388, no. 1-2, pp. 78-83, 2008.

[21] J. Delgado-Lista, F. Perez-Jimenez, J. Ruano et al., "Effects of variations in the $A P O A 1 / C 3 / A 4 / A 5$ gene cluster on different parameters of postprandial lipid metabolism in healthy young men," Journal of Lipid Research, vol. 51, no. 1, pp. 63-73, 2010.

[22] K. L. Chien, W. H. Fang, H. C. Wen et al., "APOA1/C3/A5 haplotype and risk of hypertriglyceridemia in Taiwanese," Clinica Chimica Acta, vol. 390, no. 1-2, pp. 56-62, 2008.

[23] J. A. Hubacek, R. Bohuslavova, Z. Skodova, J. Pitha, D. Bobkova, and R. Poledne, "Polymorphisms in the APOA1/C3/ $A 4 / A 5$ gene cluster and cholesterol responsiveness to dietary change," Clinical Chemistry and Laboratory Medicine, vol. 45, no. 3, pp. 316-320, 2007.

[24] M. Ashokkumar, N. G. V. Subhashini, R. Saibabu, A. Ramesh, K. M. Cherian, and C. Emmanuel, "Genetic variants on apolipoprotein gene cluster influence triglycerides with a risk of coronary artery disease among Indians," Molecular Biology Reports, vol. 37, no. 1, pp. 521-527, 2010.

[25] Z. K. Liu, M. Hu, L. Baum, G. N. Thomas, and B. Tomlinson, "Associations of polymorphisms in the apolipoprotein A1/C3/ $A 4 / A 5$ gene cluster with familial combined hyperlipidaemia in Hong Kong Chinese," Atherosclerosis, vol. 208, no. 2, pp. 427432, 2010.

[26] E. A. Ruiz-Narváez, Y. Yang, Y. Nakanishi, J. Kirchdorfer, and H. Campos, "APOC3/A5 haplotypes, lipid levels, and risk of myocardial infarction in the Central Valley of Costa Rica," Journal of Lipid Research, vol. 46, no. 12, pp. 2605-2613, 2005.
[27] M. Fiegenbaum, F. M. de Andrade, and M. H. Hutz, "Association between plasma lipid parameters and APOC3 genotypes in Brazilian subjects: effect of gender, smoking and $A P O E$ genotypes," Clinica Chimica Acta, vol. 380, no. 1-2, pp. 175$181,2007$.

[28] H. Jakel, M. Nowak, A. Helleboid-Chapman, J. FruchartNajib, and J. C. Fruchart, "Is apolipoprotein A5 a novel regulator of triglyceride-rich lipoproteins?" Annals of Medicine, vol. 38 , no. 1, pp. 2-10, 2006. 


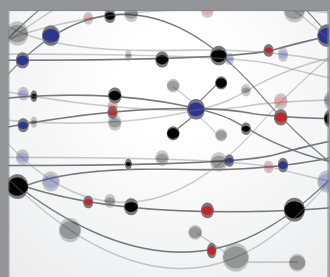

The Scientific World Journal
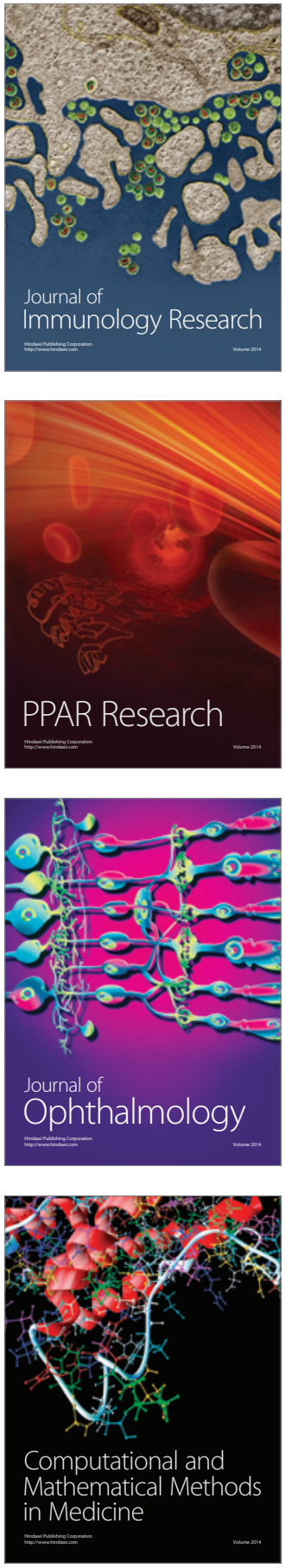

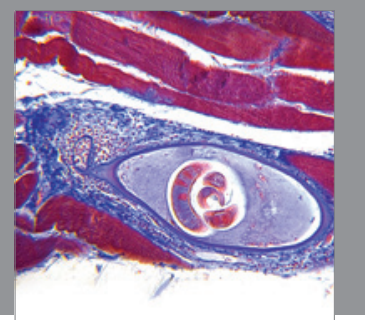

Gastroenterology

Research and Practice
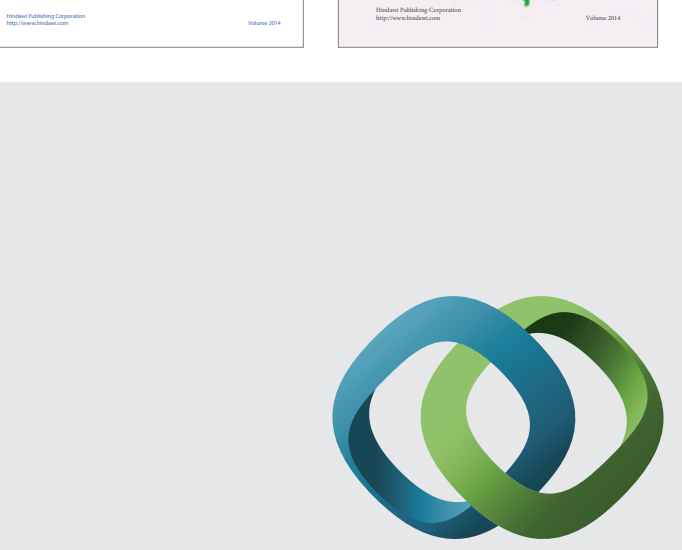

\section{Hindawi}

Submit your manuscripts at

http://www.hindawi.com
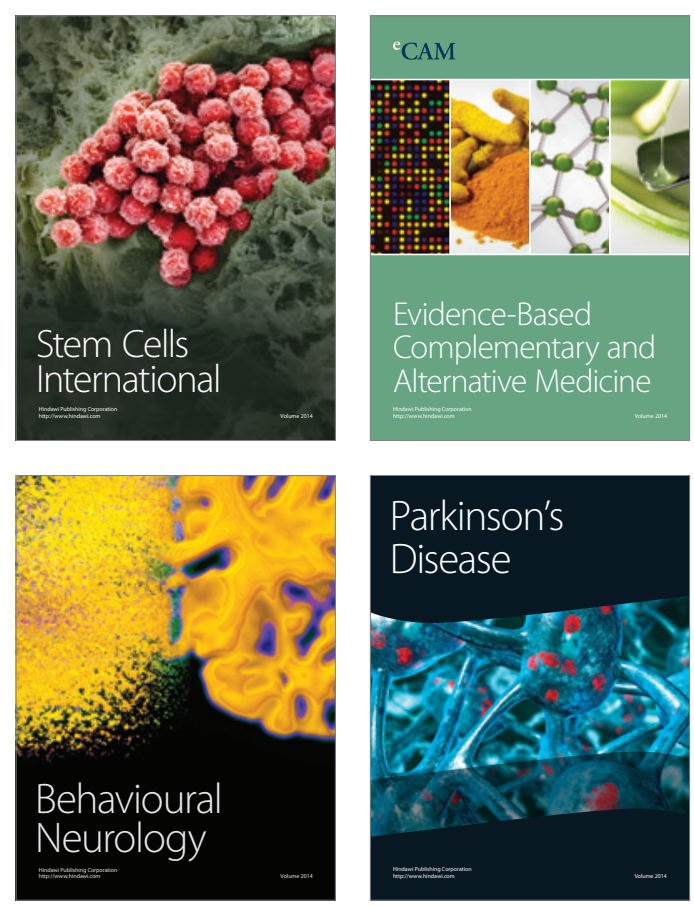

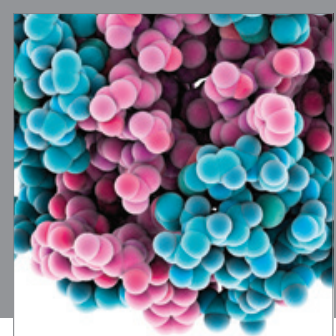

Journal of
Diabetes Research

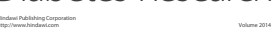

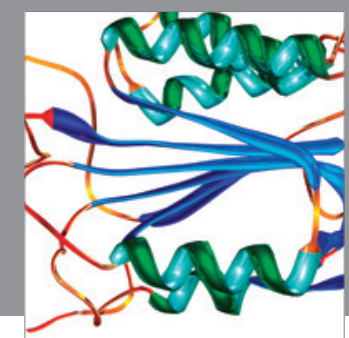

Disease Markers
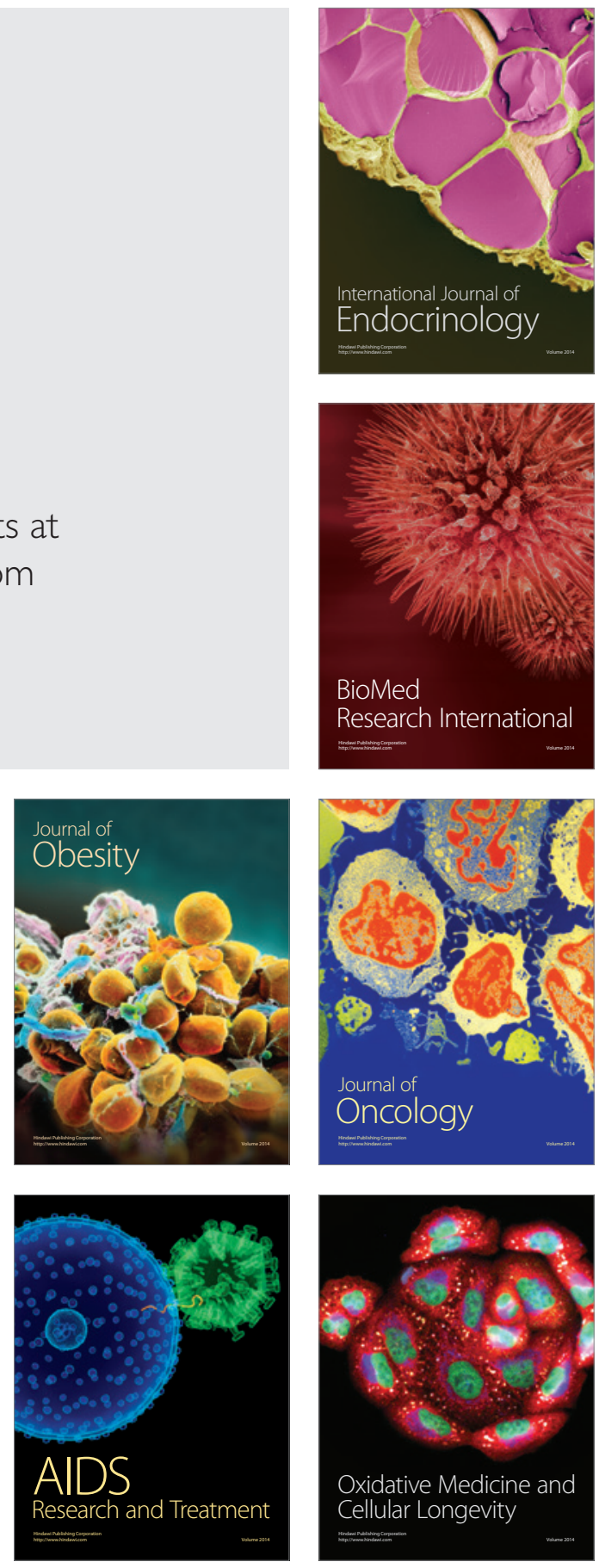